\title{
O PAPEL DO ESTADO-NAÇÃO NAS POLÍTICAS PÚBLICAS INDÍGENAS: A REALIDADE BRASILEIRA
}

\section{THE ROLE OF THE NATION-STATE IN THE INDIGENOUS PUBLIC POLICIES: THE BRAZILIAN REALITY}

\author{
Eduardo Barbuto Bicalhoi \\ Bruno Mattos de Fariasii \\ Kátia Eliane Santos Avelariii \\ Patrícia Maria Dusekiv
}

\begin{abstract}
Resumo: O presente artigo pretende discutir as dificuldades que o estado-nação vem enfrentando em razão das mudanças econômicas, políticas e culturais decorrentes da globalização, bem como a necessidade de se reformular a ideia de Estado, entendendo que ele não é mais o único ator presente no cenário internacional. Objetiva também evidenciar a desvinculação do Estado com uma determinada identidade, mostrando que a identidade advém da cultura, a qual está ligada ao sentimento de pertencimento. Por fim, procura vislumbrar o campo de atuação do Estado no cenário global, especificamente no desenvolvimento de políticas públicas em prol das minorias étnicas localizadas no território, como no caso dos indígenas no Brasil.
\end{abstract}

\footnotetext{
i Graduado em Direito pela Universidade Federal do Rio de Janeiro. Especialista em Direito Público pela Universidade Cândido Mendes. Mestre em Direito (UCAM). Mestre em Direito pela Universidade Federal do Estado do Rio de Janeiro (UNIRIO), como foco em direitos humanos e políticas públicas. ii Mestre em Desenvolvimento Local pelo Centro Universitário Augusto Motta (UNISUAM). Graduado em Arquitetura pela UNISUAM. Especialista em Educação.

iii Mestre em Ciências Biológicas pela Universidade Federal do Rio de Janeiro (UFRJ) (1996). Doutora em Ciências também pela Universidade Federal do Rio de Janeiro (2002). Atualmente é coordenadora do Laboratório de Referência Nacional para Leptospirose do Instituto Oswaldo Cruz (FIOCRUZ). Professora Titular e Pesquisadora do Programa de Pós-Graduação Profissional Interdisciplinar em Desenvolvimento Local do Centro Universitário Augusto Motta (UNISUAM).

iv Pós Doutora pela Universitá di Pisa (2015). Doutora em Direito pela Universidade Veiga de Almeida (2014). Mestre em Direito pela Universidade Cândido Mendes, onde também obteve o título de graduação na mesma área. Especialista em Direito pela EMERJ. Pesquisadora e membro da Comissão de Pesquisa da Universidade Castelo Branco - UCB. Parecerista ad hoc de Revistas Científicas. Professora da Universidade Castelo Branco e do Centro Universitário de Barra Mansa. Articulista, palestrante e conferencista bilíngue em eventos nacionais e internacionais.
} 
Palavras-chave: Estado. Direito. Identidade. Políticas públicas.

\begin{abstract}
The present article intends to discuss the difficulties that the Nation-State is facing due to the economic, political and cultural changes resulting from globalization, as well as the need to reformulate the idea of State, understanding that it is no longer the only actor present in the international scene. It also aims to demonstrate the untying of the state with a certain identity, showing that the identity comes from the culture, which is linked to the feeling of belonging. Finally, it seeks to envisage the State's field of action in the global scenario, specifically in the development of public policies in favor of ethnic minorities located in the territory, as in the case of indigenous people in Brazil.
\end{abstract}

Keywords: State. Law. Identity. Public Policies. 


\section{INTRODUÇÃO}

O presente artigo tem por objeto estudar os elementos estado-nação, identidade e globalização, no que se refere à compreensão desses termos, à interação entre os mesmos e às consequências práticas dessa relação.

Busca compreender como a ideia do estado-nação vem sendo alterada pelas inúmeras mudanças resultantes do processo de globalização econômica, política e cultural, o que, necessariamente, passa pela compreensão do que significa identidade.

Ressalta-se que na atualidade diversas questões vêm afetando sobremaneira a organização da arena internacional e principalmente o modo de interação entre os atores da cena global, tais como a nova soberania dos Estados, os fluxos migratórios, a interferência da tecnologia, os mercados globais, as minorias étnicas, a cultura dos povos etc.

Essas questões continuam na ordem do dia dos profundos debates envolvendo a globalização da economia, da política e da cultura, aos quais vivenciamos profundamente em nossos dias e que nos levam a repensar diversos conceitos que até poucas décadas atrás nos pareciam sólidos e inabaláveis.

O primeiro ponto a ser discutido neste artigo é a redefinição do Estado Nacional e o surgimento de novos atores nos processos deliberativos internacionais, ou seja, aquela ideia do Estado como a união entre soberania, povo e território deixa de ser tida como absoluta e ganha novos contornos, uma vez que se permite visualizar Estados Pluriétnicos e "Multissocietários".

Após, pretende-se analisar o conceito de identidade, a fim de demonstrar o caráter cultural de tal conceito e, ao mesmo tempo, seu viés espontâneo, ou seja, a forma natural pela qual os costumes, os valores e o sentimento de pertencimento vão se imiscuindo na sociedade e tornando-a uma cultura única, diferenciada, ou até mesmo uma etnia.

Em sequência, pretendemos verificar como tais conceitos se desenvolvem diante de um mundo globalizado, não apenas economicamente, mas culturalmente e politicamente, contrapondo universalismos e particularismos e evidenciando o grande paradoxo da globalização, segundo o qual quanto mais cresce o mundo global, mais crescem as forças contrárias ao mesmo. 
Então, relacionaremos os pontos acima identificados, com o objetivo de demonstrar como a globalização e o surgimento dos novos atores internacionais influenciam na forma com que os Estados Nacionais lidam com as minorias étnicas situadas em seus territórios.

Por fim, verificaremos como as relações entre os temas estudados podem ser aplicadas no Brasil, ou seja, como o Estado Brasileiro se relaciona com as minorias étnicas presentes em seu território, especificamente as indígenas.

\section{A RECONCEITUAÇÃO DO ESTADO NACIONAL}

De fato, o mundo não é mais o mesmo. Desde o surgimento dos Estados Nacionais até a atualidade, o estado-nação se modificou de forma intensa e ainda está se modificando ao se deparar com contingências variadas.

Em seu momento inicial surgiu como o grande defensor da segurança de seus cidadãos, era forte e soberano, se justificava pela necessidade de manutenção da vida e integridade física das pessoas, era um Estado defensor, que precisava ser forte para se proteger contra invasões externas e revoltas internas.

Assim, podemos descrever o mundo nesse período como sendo formado por estados-nação apenas, os quais representavam os seus respectivos povos. Essa ideia se coaduna à visão do Estado como sendo a união entre soberania, povo e território, ou seja, o povo localizado em um determinado território compunha uma nação, a qual era liderada pelo poder político majoritário naquele país, que consiste na elite dominante a cada tempo.

Essa noção também pressupunha uma igualdade de identidade, isto é, cada Estado era formado de apenas um povo, uma nação. A França era a nação formada apenas por franceses, a Inglaterra por ingleses, o Brasil por brasileiros e assim por diante. Bauman descreve o estado-nação moderno da seguinte forma:

Nos tempos modernos, a nação era a 'outra face' do Estado e a arma principal em sua luta pela soberania sobre o território e sua população. Boa parte da credibilidade da nação e de seu atrativo como garantia de segurança e de durabilidade deriva de sua associação íntima com o Estado e - através dele - com as ações que buscam construir a 
certeza e a segurança dos cidadãos sobre um fundamento durável e confiável, porque coletivamente assegurado. (BAUMAN, 1988, p. 211)

Ocorre que isso foi mudando ao longo do tempo e tal movimento se intensificou nas últimas décadas em razão, principalmente, dos seguintes fatores:

A globalização econômica: a interação entre os mercados locais foi crescendo de tal forma que hoje temos um mercado global. As práticas comerciais não têm fronteiras estatais e as empresas se tornaram multinacionais e até mesmo globais, possuindo capital, insumos e pessoas provenientes de diversos Estados-nação;

A globalização financeira: na atualidade, as finanças de um país refletem em outro ou até em todo o mundo. Não é mais possível um Estado organizar sua economia internamente sem considerar os reflexos das variações nas finanças globais. A taxa de juros, a inflação, as bolsas de valores, a cotação de moedas estrangeiras, as ações de grandes empresas, tudo isso influencia na economia interna de um país;

A globalização política: os países se reuniram em blocos que, a princípio, foram econômicos, mas cada vez mais se tornam culturais e políticos, como ocorre hoje na União Europeia, onde o bloco vem influenciando os Estados a modificarem posturas e valores internos;

A inovação tecnológica: a grande evolução dos transportes e da tecnologia da informação revolucionou o mundo no último século, aproximando distâncias incalculáveis e propiciando inúmeros fluxos migratórios por todo o mundo.

De fato, esses elementos propiciaram grandes mudanças. Hoje em dia, é possível que um indivíduo de uma nacionalidade se mude para outro país, mas mantenha seus laços e costumes de origem, diante das possibilidades tecnológicas de comunicação instantânea como o telefone e a internet.

Aliado a isso, há também a mudança do mundo, de uma "modernidade sólida" para uma "modernidade líquida", conforme esclarecido por Bauman. A primeira seria justamente a que tem início com as transformações clássicas e o advento de um conjunto estável de valores e modos de vida cultural e político. Na modernidade líquida, tudo é volátil, as relações humanas não são mais tangíveis e a vida em conjunto, familiar, de casais, de grupos de amigos, de afinidades políticas e assim por diante, perde consistência e estabilidade. 
Nas palavras de Bauman:

Umavezqueas crenças, valores eestilos foram "privatizados" - descontextualizados ou "desacomodados" com lugares de reacomodação que mais lembram quartos de motel que um lar próprio e permanente - as identidades não podem deixar de parecer frágeis e temporárias, e despidas de todas as defesas exceto a habilidade e determinação dos agentes que se aferram a elas e as protegem da erosão. A volatilidade das identidades, por assim dizer, encara os habitantes da modernidade líquida. (BAUMAN, 1998, p. 204).

Diante de todos esses fatores, surgiram novos atores políticos e econômicos que passaram a dividir com o estado-nação a participação no mundo e, consequentemente, identificamos uma redução da soberania estatal. Esses novos atores podem ser divididos em supraestatais, como as organizações internacionais e as empresas globais e infraestatais, como grupos socais e étnicos.

De fato, existem conglomerados econômicos mais poderosos e mais ricos do que muitos Estados e tais empresas controlam, muitas vezes, políticas estatais, uma vez que possuem a hegemonia econômica em um determinado país. Não é possível para o Estado competir com tais forças, uma vez que precisa delas para a geração de empregos e renda.

Também os organismos internacionais promovem campanhas capazes de influenciar a opinião pública global e gerar consequências em políticas públicas internas dos Estados, como ocorre com movimentos pacifistas, green peace, dentre outros.

Nesse sentido, explica lanni:

Se é verdade que a globalização do mundo está em marcha, e tudo indica que sim, então começou a réquiem pelo estado-nação. Ele está em declínio, sendo redefinido, obrigado a rearticular-se com as forças que predominam no capitalismo global e, evidentemente, forçado a reorganizar-se internamente, em conformidade com as injunções dessas forças. É claro que o estado-nação, com sua sociedade nacional, histórica, geografia, cultura, tradições, língua, dialetos, religião, seitas, moeda, hino, bandeira, santos, heróis, monumentos, ruínas continuará a existir. Mas não será mais o mesmo, isto é, já não é mais o mesmo. (IANNI, 1996, p. 121-122). 
Assim, é preciso reconceituar o Estado Nacional e entender o seu novo papel no mundo global. Em verdade, como informa o texto de lanni acima, não é possível prever o fim do estado-nação, pois o mesmo ainda mantém uma posição de elevada importância no cenário mundial, mas agora não é o único ator e precisa se sujeitar, não raras vezes, à vontade dos novos participantes desse espaço.

Nesse contexto, o Estado ainda mantém grande importância porque internamente ainda é o único detentor do poder de império, podendo regular a entrada e a saída de pessoas, emitir passaporte, tributar e exercer o monopólio da força física. Contudo, suas ações estão condicionadas aos demais interesses em jogo. Nesse sentido, Anderson:

Para concluir, deixem-me dizer que creio que o Estadonação ainda permanecerá, por um bom tempo, como a unidade política legítima básica do século XXI, apesar de já ter alcançado seu apogeu histórico, que começa a ser superado. Mais importante: há poderosas mudanças a caminho, quanto ao significado que o hífen pode passar a ter na expressão, o mesmo hífen que tornou possível o casamento entre nação e Estado ao longo dos séculos XIX e XX. (ANDERSON, 1999, p. 169).

Especificamente em matérias de políticas públicas, é importante ressaltar que elas, em regra, se traduzem em ações estatais com o objetivo de se efetivar algum direito constitucionalmente garantido aos cidadãos, tais como educação, saúde, moradia e também outros ligados a direitos individuais, como a participação política, o acesso à justiça, liberdade de crença etc.

No mundo global, os Estados não são independentes para formular e implementar políticas públicas, já que, como veremos mais adiante, a efetivação de certos direitos pode atingir interesses contrários de grupos políticos e econômicos. Então cabe ao Estado essa mediação, a fim de ajustar os interesses em conflito e alcançar saídas alternativas capazes de atender aos mandamentos constitucionais.

\section{IDENTIDADE COMO OBJETO CULTURAL}

Nesse item buscaremos mostrar o nosso entendimento sobre a questão da identidade e alguns de seus desdobramentos sociais. O que, de fato, faz com que o indivíduo sinta-se pertencente a um grupo de pessoas? Para entender tal sentimento é preciso aclarar algumas questões a respeito da cultura. 
A cultura, conforme orientações de Laraia (2008), é um elemento da vida em sociedade que surge em um momento determinado da evolução humana no qual o homem é capaz de desenvolver certas habilidades, como a comunicação, por exemplo. Para existir, a cultura depende da transmissão entre as pessoas, de algo racional, uma vez que ultrapassa a seara dos instintos. Não pode ser definido como cultura o fato do homem procurar alimento e se proteger contra perigos, isso é instintivo. Cultura consiste em práticas e valores que não são necessariamente iguais a todo o ser humano.

Por outro lado, a cultura também não é algo puramente racional, pois é dotada de forte caráter espontâneo. Ela não é pensada por estudiosos, mas sim praticada, criada no dia-a-dia do grupo social, vai se desenvolvendo e se torna rotineira, costumeira, como a língua ou, para a Escola Histórica, o próprio Direito.

Outro fator importante é que a cultura também não é algo biológico, registrado no DNA dos homens, já que se um índio for levado à Europa recém-nascido, é certo que irá viver como um europeu, assimilando a cultura do local onde se desenvolver.

Assim, Laraia (2008) explica que na cultura prevalece o caráter de aprendizado em oposição à ideia da aquisição inata ${ }^{1}$. Nela se reúne uma série de fatores como crenças, arte, moral, leis, costumes, tradições etc.

Assim, o sentimento de pertencimento está ligado a uma série de características que tornam certos homens mais "iguais" do que outros, por possuírem as mesmas culturas e tradições. Muitos Estados Nacionais, quando de sua formação, buscaram igualar todos os cidadãos em uma mesma cultura, criando símbolos, histórias, ídolos comuns e sufocando aqueles que mantinham traços relevantes distintos, num processo conhecido como assimilação cultural.

Porém, nas últimas décadas, como já dito acima, as fronteiras nacionais não são mais fronteiras culturais e étnicas. A necessidade do mercado se impôs sobre a necessidade de uma cultura comum, pois os recursos humanos necessários estão sendo buscados em qualquer parte do mundo e a necessidade de emprego leva milhares de migrantes a se estabelecer em outros territórios, mantendo suas culturas de origem.

De fato, as migrações mudaram o cenário dos países, é comum se ter uma segunda categoria de cidadãos dentro do mesmo estado-nação,

1 O texto de Laraia (2008) se refere à John Locke e o que foi por ele chamado de "caixa vazia". Assim, refuta a ideia pela qual princípios e verdades são impressos hereditariamente na mente humana. 
o qual passa a ser formado por mais de uma etnia. Existe a cultura global, que é consumida por todo o mundo e a cultura nacional, que permanece vigente. Nesse sentido defende Anderson:

Dessas transformações decorrem novas 'identidades' desterritorializadas e 'nacionalidades portáteis'. Algumas identidades são efetivamente nacionalistas, mas há também poderosas coalizões de gênero, como a das feministas ou a dos homossexuais; associações de grupos religiosos, grupos de povos nativos etc. - e elas se tornam cada vez mais interativas, talvez como nunca tenham sido anteriormente. (ANDERSON, 1999, p. 168)

O paradoxo nesse novo mundo é que quanto mais o movimento da globalização se aprofunda, mais crescem organizações que visam fortalecer os particularismos e reduzir a homogeneização cultural capitalista. É o que encontramos fortemente nos países islâmicos, os quais, enraizados muitas vezes no fundamentalismo religioso, reagem contra o avanço da sociedade global, a fim de valorizar as tradições de seus povos.

Surge, então, um novo ator no cenário mundial, o terrorismo, o qual acarreta o declínio da confiança das pessoas no estado-nação e, consequentemente, o nível de colaboração cai e o Estado enfraquece. Por outro lado, a necessidade de combater o terrorismo também contribui para a redução da soberania estatal, uma vez que é necessário apoio externo e uma soberania compartilhada. Outra consequência é a restrição de direitos fundamentais por parte dos Estados como forma de garantia da segurança das pessoas contra o terrorismo.

Assim, é preciso visualizar uma nova forma de lidar com um mundo onde os particularismos se entrelaçam e isso requer, acima de tudo, tolerância. Respeitar outras etnias é o primeiro passo para se conviver no mundo globalizado, visando não mais a assimilação cultural e a eliminação de culturas, mas o convívio pacífico.

\section{MUNDO GLOBALIZADO E A FORÇA DAS POTÊNCIAS ECONÔMICAS E TECNOLÓGICAS}

Com base no que foi dito acima, é preciso compreender como as novas relações advindas da globalização em todas as suas facetas interfere na questão da identidade dos povos, de sua cultura e como isso afeta o estado-nação. 
Tradicionalmente, o estado-nação tende a ser contra as minorias. Era preciso gerar uma identidade única a fim de fortalecer o Estado e permitir sua manutenção. Mas hoje, o Estado, para se sustentar no mundo capitalista, depende dos recursos econômicos dos grandes conglomerados empresariais e financeiros, seja para obtenção de crédito, geração de empregos, arrecadação de tributos e para consumir a tecnologia por eles produzida.

$\mathrm{Na}$ atualidade, existem bens imateriais que valem, muitas vezes, mais que ativos econômicos, tais como a tecnologia e o conhecimento. Os Estados periféricos dependem da tecnologia desenvolvida por empresas dos Estados Centrais e também das empresas supraestatais ou globais, em vários campos, como a produção de armas, de energia, o processamento de dados, dentre outros.

Assim, não podemos mais conceber a soberania do Estado como antes, como algo sólido, intacto, mas sim como algo maleável, que abre caminhos para essas novas forças globais tão importantes no mundo atual. A soberania é mitigada, os Estados não estão totalmente livres para escolher suas prioridades, tampouco o momento e o modo de agir, pois dependem da aprovação das demais forças interessadas. Para o mercado, quanto mais fraco for o estado-nação, melhor. Nas palavras de Bauman, citando Hobsbawm:

Para as multinacionais (isto é, empresas globais com interesses e compromissos locais dispersos e cambiantes), 'o mundo ideal' 'é um mundo sem Estados, ou pelo menos com pequenos e não grandes Estados', observou Eric Hobsbawm. 'A menos que tenha petróleo, quanto menor o Estado, mais fraco ele é, e menos dinheiro é necessário para se comprar um governo'. (BAUMAN, 1998, p. 219)

Por isso que, em muitos casos, ações ambientais são postergadas para não prejudicar algum empreendimento comercial importante, ações sociais são arquivadas para permitir a continuidade de uma empresa em determinado local ou a venda de certos produtos, isenções tributárias são concedidas, reduzindo a arrecadação estatal, dentre outros exemplos.

Além disso, muitos assuntos internos dependem dos atores internacionais, os quais definem o valor da moeda nacional, os juros internos, o consumo, os preços etc. Assim, é possível concluir que o projeto nacional é influenciado pela nova realidade global. Os Estados-nação 
mais poderosos, juntamente com os conglomerados econômicos multinacionais, dão as cartas nos fóruns internacionais, controlando os organismos e influenciando as decisões internas dos países periféricos.

Importante ressaltar que esse viés negativo não é o único, já que essas empresas também contribuem com o crescimento do país, a redução do desemprego, a geração de renda e de consumo, a arrecadação de tributos etc. Contudo, o ponto negativo é a subordinação do Estado a essas entidades, pois juntamente com o Estado está a gestão imparcial dos interesses da população, não apenas econômicos, mas de diversas outras ordens.

O empreendedorismo capitalista, ainda que contribua com o bem -estar social, sempre vai ter por fim o seu próprio lucro, direto ou indireto. Se uma ação social não produz tal resultado, a mesma não terá continuidade. O Estado Social, porém, possui outra lógica, que é a da igualdade entre os cidadãos, a da solidariedade, a da distribuição de renda e a da garantia do mínimo existencial para todas as classes e tipos de pessoas.

Sendo assim, o Estado precisa se adequar à nova realidade, abrindo espaços para a não subordinação à força do capital privado, na medida do possível, além de adaptar as questões nacionais às demandas multinacionais. Precisa manter o seu direito de estabelecer prioridades para o país, mas sem prescindir do capital internacional. Até mesmo porque nos dias de hoje os Estados não têm muita escolha quanto à sua participação na sociedade global, conforme orienta Bauman:

Muitas vezes a punição é econômica. Governos insubordinados, culpados de políticas protecionistas ou provisões públicas generosas para os setores 'economicamente dispensáveis' de suas populações e de não deixar o país à mercê dos 'mercados financeiros globais' e do 'livre comércio global', têm seus empréstimos recusados e negada a redução de suas dívidas; as moedas locais são transformadas em leprosas globais, pressionadas à desvalorização e sofrem ataques especulativos; as ações locais caem nas bolsas globais; o país é isolado por sanções econômicas e passa a ser tratado por parceiros comerciais passados e futuros como um pária global; (...) Se a demonstração diária e rotineira da superioridade das forças globais não for suficiente para forçar o Estado a ver a razão e cooperar com a nova 'ordem mundial', a força militar é exercida. (BAUMAN, 1998, p. 212 a 213) 


\section{ESTADO-NAÇÃO, IDENTIDADE, GLOBALIZAÇÃO E MINORIAS ÉTNICAS}

Após compreendermos as características atuais do mundo globalizado e suas interferências sobre a identidade e o Estado Nacional, é preciso estudar como esse contexto interfere na posição das minorias étnicas existentes.

De fato, em diversos Estados existentes no globo existem minorias étnicas, ou seja, grupos de indivíduos que possuem outra identidade, nos termos já discorridos neste trabalho. Ocorre que essas pessoas, na maioria das vezes, se encontram alijadas dos processos políticos e econômicos dominantes no Estado, situando-se fora da sociedade nacional.

Diversas são as formas que os Estados lidam com tais minorias, mas é crescente no mundo, até mesmo em razão do fortalecimento dos direitos humanos nas últimas décadas, a ideia de que os indivíduos pertencentes a minorias étnicas devem ter os mesmos direitos que os integrantes da sociedade nacional, porém, com respeito à diversidade cultural existente.

Nem todos os países reconhecem tal realidade, perpetuando assim o histórico de isolamento, discriminação e miséria de minorias. Outros, porém, reconhecem juridicamente outras identidades localizadas no território do Estado, mas não promovem, de fato, nenhuma ação capaz de produzir melhorias para as populações alijadas. Por último, há Estados que efetivam políticas públicas para a integração das minorias e manutenção de sua identidade cultural.

Conforme apontado no texto de Pierré-Caps (2004), existem alguns tipos de reconhecimento cultural de minorias étnicas: o internacional, o interno, o constitucional, o legislativo e o implícito, a saber:

- Internacional - por força de tratados internacionais, instrumentos de proteção a minorias entram nos ordenamentos jurídicos nacionais, traduzindo-se num ato de reconhecimento interestatal;

- Interno - é o reconhecimento pelo próprio Estado, o qual pode se dar em níveis mais ou menos elevados, a depender da localização da regra jurídica, se em nível constitucional ou não, bem como da terminologia utilizada ao se referir ao povo minoritário;

- Constitucional - ocorre quando o reconhecimento ao fator minoritário se dá na própria constituição do Estado, o que é bem raro no cenário mundial; 
- Legislativo - quando o reconhecimento se dá em textos infraconstitucionais, os quais são, em regra, mais prolixos e, certamente, dotados de menos força que as regras constitucionais;

- Implícito - "as minorias, sem se beneficiar de um reconhecimento expresso em nível constitucional ou legislativo, são contudo objeto de textos diversos e circunstanciais, de nível legislativo ou administrativo, concernentes, por exemplo ao uso da língua minoritária e até de questões mais específicas relativas a grupos determinados."

Por outro lado, há também um tipo de reconhecimento externo, ou seja, de fora para dentro, que ocorre quando o Estado reconhece, mediante critérios por ele estabelecidos, as pessoas que integram uma minoria étnica. Por outro lado, o reconhecimento interno é aquele em que os próprios indivíduos se intitulam como pertencentes ou não a uma minoria cultural.

Assim, o reconhecimento jurídico das minorias étnicas passa pela afirmação da identidade minoritária e pelo direito à autodeterminação. Contudo, muitos países não realizam tal reconhecimento, tratando os direitos das minorias étnicas no bojo dos direitos individuais tradicionalmente concebidos e positivados, como a liberdade de crença, o direito à vida e à integridade física, direito de reunião e de resistência à opressão, dentre outros, mas sem, de fato, diferenciar a cultura, permitir formas próprias de representação e manifestação, com o reconhecimento das características peculiares daquele povo. No exemplo de Pierré-Caps:

\begin{abstract}
(...) a introdução da liberdade de consciência e de religião no sistema geral de garantia e de proteção dos direitos não vale, portanto, para o reconhecimento de uma minoria religiosa desde que tal liberdade se relacione com o indivíduo e não com o grupo constituído em razão de uma identificação de natureza religiosa. (PIERRÉ-CAPS, 2004, p. 281-282).
\end{abstract}

Em outros países, como a Bolívia, por exemplo, é possível verificarmos a existência de um verdadeiro sistema jurídico que contempla especificidades das minorias étnicas que lá residem, inclusive com formas próprias de resoluções de conflitos que contemplam as tradições do referido povo. 
Com efeito, os Estados Nacionais precisam conciliar dois interesses importantes: a cultura predominante, da sociedade nacional, a ordem jurídica vigente, os direitos e garantias fundamentais previstos em sua Constituição e também as práticas, costumes e tradições minoritários.

Assim, o Estado não pode sufocar as minorias étnicas com o objetivo da assimilação cultural e o desaparecimento desses povos, mas também não pode aceitar a derrogação dos valores da sociedade nacional incutidos nos princípios constitucionais. Essa situação é demonstrada por Pierré-Caps nos dois pontos abaixo:

Em primeiro lugar, a valorização da identidade minoritária deve ser modulada e controlada de tal modo que ela não possa desembocar no direito à autodeterminação no sentido do direito à independência;

Em segundo lugar, a afirmação do direito à diferença deve ser compatível com a construção da nação estatal, projeto reivindicado por todo Estado-nação. (PIERRÉCAPS, 2004, p. 280)

Nesse contexto, podemos citar o exemplo de uma minoria étnica que pratique, de forma cultural, o ato de matar crianças com doenças congênitas, sendo que tal grupo de pessoas se localizam no interior de um Estado Democrático de Direito. O que deve fazer o Estado Nacional?

O Estado Nacional deve compatibilizar os interesses em conflito, tendo sempre por base os seguintes valores: a tolerância com as diferenças e o respeito à Constituição. Assim, práticas violadoras de direitos humanos devem ser reprimidas, mas não da mesma forma que ocorre com criminosos dentro da sociedade nacional. É preciso que haja políticas públicas capazes de provocar a alteração dessas práticas, mas sem eliminar ou assimilar as demais tradições do referido povo.

É nesse conjunto de ideias também que se desenvolve um grande problema da atualidade, que é a concepção comum de que as minorias, principalmente aquelas que estão ligadas tradicionalmente a uma determinada área territorial (autóctones), são um empecilho ao desenvolvimento econômico e social do Estado.

Isso ocorre porque muitas vezes as áreas ocupadas por essas populações são de interesse de conglomerados econômicos, em razão de possuírem recursos naturais importantes, como o petróleo, o gás natural, os minérios, a biodiversidade, entre outros. Dessa forma, a criação de reservas naturais para a habitação de populações tradicionais entram em 
choque com os interesses econômicos, os quais, como já dito acima, possuem importante participação no cenário político nacional e mundial, com poderio econômico e tecnológico muitas vezes superior a Estados inteiros e, por isso, com grande influência sobre as políticas governamentais.

É preciso, portanto, que haja o reconhecimento das minorias, pois a falta dele, inclusive em termos jurídicos, equivale à negação da existência das minorias. Assim, não basta que haja o reconhecimento de direitos individuais, mas que o exercício desses direitos ocorra de forma coletiva.

Dessa forma, o Estado precisa se reposicionar nesse mundo pósmoderno, compreender os seus limites e também a força que ainda tem, de modo a ponderar os interesses em conflito, agir com tolerância e elaborar políticas públicas que conciliem o desenvolvimento e o respeito às tradições culturais das minorias, reconhecendo juridicamente as minorias de forma coletiva, dando representatividade aos grupos étnicos e permitindo que estes tenham voz e possam lutar pelos seus interesses.

\section{O CASO BRASILEIRO E A QUESTÃO INDÍGENA}

O caso indígena no Brasil é um problema público que já se desenvolve desde o "descobrimento" do território pelos portugueses e é marcado pela dominação da cultura européia sobre a indígena, resultando na extinção de milhares de índios e na não participação desses povos na política e economia da sociedade nacional.

A Constituição da República de 1988 reconheceu os índios como uma cultura própria pertencente ao Estado Brasileiro, conforme artigos 231 e 232 abaixo:

Art. 231. São reconhecidos aos índios sua organização social, costumes, línguas, crenças e tradições, e os direitos originários sobre as terras que tradicionalmente ocupam, competindo à União demarcá-las, proteger e fazer respeitar todos os seus bens.

$\S 1^{\circ}$ - São terras tradicionalmente ocupadas pelos índios as por eles habitadas em caráter permanente, as utilizadas para suas atividades produtivas, as imprescindíveis à preservação dos recursos ambientais necessários a seu bem-estar e as necessárias a sua reprodução física e cultural, segundo seus usos, costumes e tradições.

$\S 2^{\circ}$ - As terras tradicionalmente ocupadas pelos índios destinam-se a sua posse permanente, cabendo-lhes 0 
usufruto exclusivo das riquezas do solo, dos rios e dos lagos nelas existentes.

$\S 3^{\circ}$ - O aproveitamento dos recursos hídricos, incluídos os potenciais energéticos, a pesquisa e a lavra das riquezas minerais em terras indígenas só podem ser efetivados com autorização do Congresso Nacional, ouvidas as comunidades afetadas, ficando-lhes assegurada participação nos resultados da lavra, na forma da lei.

$\S 4^{\circ}$ - As terras de que trata este artigo são inalienáveis e indisponíveis, e os direitos sobre elas, imprescritíveis.

$\S 5^{\circ}$ - É vedada a remoção dos grupos indígenas de suas terras, salvo, "ad referendum" do Congresso Nacional, em caso de catástrofe ou epidemia que ponha em risco sua população, ou no interesse da soberania do País, após deliberação do Congresso Nacional, garantido, em qualquer hipótese, o retorno imediato logo que cesse o risco.

$\S 6^{\circ}$ - São nulos e extintos, não produzindo efeitos jurídicos, os atos que tenham por objeto a ocupação, o domínio e a posse das terras a que se refere este artigo, ou a exploração das riquezas naturais do solo, dos rios e dos lagos nelas existentes, ressalvado relevante interesse público da União, segundo o que dispuser lei complementar, não gerando a nulidade e a extinção direito a indenização ou a ações contra a União, salvo, na forma da lei, quanto às benfeitorias derivadas da ocupação de boa fé.

$\S 7^{\circ}$ - Não se aplica às terras indígenas o disposto no art. $174, \S 3^{\circ}$ e $\S 4^{\circ}$.

Art. 232. Os índios, suas comunidades e organizações são partes legítimas para ingressar em juízo em defesa de seus direitos e interesses, intervindo o Ministério Público em todos os atos do processo. (BRASIL, 1988).

Dessa forma, percebe-se que o Estado Brasileiro concedeu o reconhecimento jurídico aos povos indígenas de maneira coletiva, conforme a análise de Souza feita em sua tese de doutorado e abaixo transcrita:

Inovou o Constituinte ao alçar ao nível constitucional quanto à inclusão das organizações representativas das comunidades (art. 232, CF), aí incluindo os grupos tribais de que fala a lei ordinária e, em conseqüência, transformando a personalidade jurídica de fato em personalidade jurídica de direito público, pois que gozando a proteção Estado. 
Todavia, uma norma constitucional vale tanto quanto tenha a capacidade de produzir efeitos, de realizar o direito reconhecido na prática e coibir e sancionar suas violações, repondo o direito eventualmente violado. Do mesmo modo se pode dizer que um regime de direitos fundamentais se caracteriza não tanto pela inscrição desses direitos no texto constitucional, mas por sua realização efetiva no plano prático. Daí porque investigar como aparelhar os direitos reconhecidos com meios de fazê-los valer, isto é, de darIhes eficácia. (SOUZA, 2002, p. 220)

Apesar disso, não se vislumbra, na prática, nenhuma política pública que, de fato, permita a inserção desse povo na realidade política do país, com respeito às tradições indígenas, e que possa conciliar os interesses de tais povos com os da sociedade nacional.

O que se vê na prática é o agronegócio cada vez mais se apropriando de terras destinadas aos índios e provocando inúmeras alterações nas culturas tradicionais, com a consequente extinção dos índios ou de suas culturas.

Então, apesar da consagração constitucional dos direitos das minorias étnicas situadas no território brasileiro, é imperioso admitir que tal norma não atingiu a eficácia devida. Assim, é preciso que a comunidade política, o Ministério Público e o Poder Judiciário trabalhem conjuntamente de modo a se alcançar a eficácia dos direitos constitucionais dos povos indígenas, efetivando assim a Constituição vigente.

Conforme os ditames do neoconstitucionalismo, em pleno vigor no Brasil desde a promulgação da Constituição de 1988, as normas constitucionais, sejam regras ou princípios, possuem força normativa. Assim, os direitos por ela garantidos são passíveis de exigência judicial, uma vez que devem se caracterizar como verdadeiros direitos subjetivos. Dessa forma, não há que se falar em norma de caráter programático em matéria de direitos fundamentais.

Por isso o Estado se encontra vinculado a prestar serviços e a criar políticas e programas públicos que permitam a efetivação dos direitos fundamentais de todos. No caso da população indígena, seus direitos constitucionais somente serão eficazes quando existirem políticas públicas inclusivas, que devem ser elaboradas e executadas com respeito às peculiaridades dos povos envolvidos e de modo a ponderar tais interesses com o desenvolvimento econômico do país, o qual também é um valor constitucional a ser defendido. 


\section{CONCLUSÃO}

Conforme demonstrado no presente trabalho, os elementos estado-nação, identidade e globalização estão interligados na atualidade, uma vez que os movimentos de reordenação da sociedade mundial afetou a hegemonia do estado-nação, bem como a identidade cultural dos povos.

Ao passo que a sociedade mundial se homogeiniza em torno de valores do capitalismo global, as pessoas modificam sua maneira de viver e se relacionar. Nesse novo mundo, a tecnologia é um novo personagem importante, permitindo o intercâmbio cultural de diversas formas, tanto pelos meios de comunicação quanto pelos de transporte.

Por outro lado, outras culturas tendem a se fechar em um particularismo mais acirrado, se recusando a ingressar na sociedade global e partindo para o isolamento ou até para movimentos como o terrorismo.

O estado-nação, apesar de menos forte e reconfigurado, precisa atuar na defesa de minorias étnicas localizadas em seu território, de modo a permitir que essas populações mantenham sua cultura, sua identidade, sem ser assimilada pela cultura da sociedade nacional. Ao mesmo tempo, esses grupos precisam ser inseridos na estrutura formal de poder, de modo a permitir sua inclusão política e a defesa de seus direitos.

Nesse contexto, cabe ao Estado equilibrar os interesses do mercado (no Brasil, particularmente, o agronegócio) com as demandas das populações minoritárias, ponderando os imperativos de desenvolvimento da economia, que é importante para a geração de riquezas e de empregos, com os valores das populações tradicionais, que não podem ser medidos economicamente.

No caso brasileiro, é preciso que se busque a eficácia dos direitos constitucionais dos povos indígenas, uma vez que já foi reconhecido pela Constituição da República de 1988 que os índios brasileiros possuem uma série de direitos, sendo inclusive reconhecido o tratamento coletivo dos mesmos, como de fato deve ser.

Contudo, na prática, as tribos continuam sofrendo a pressão do agronegócio e se veem num conflito entre a perda contínua das áreas que secularmente habitam ou a assimilação que a cultura predominante impõe.

Assim, são necessárias políticas públicas que se baseiem nos valores da tolerância e do respeito às diferenças, de modo a permitir que 
as populações minoritárias sejam incluídas na vida social e política, sem perder a sua identidade, ou seja, o seu reconhecimento como parte de um grupo em particular, o seu pertencimento a uma cultura diversa, mas respeitada e reconhecida pelo Estado.

Por fim, cabe ressaltar o trecho do Professor SOUZA (2002), que nos permite concluir que os DESCA (direitos econômicos, sociais, culturais e ambientais) devem ser garantidos pelo Estado por força constitucional e a ampliação dos espaços dos DESCA no Brasil tem como pressuposto a adoção de um amplo leque de estratégias. No âmbito das ações nacionais, os movimentos de direitos humanos precisam desenvolver estratégias de reivindicação do DESCA, através de pelo menos três caminhos, a justiciabilidade (enquanto possibilidade de se exigir direitos face ao Poder Judiciário), as políticas públicas e o monitoramento. Quando combinados esses três mecanismos poderão garantir a realização dos DESCA num período de tempo mais curto. A preocupação com a questão tempo é uma preocupação que se vincula e se compatibiliza com a emergência de realização dos DESCA.

\section{REFERÊNCIAS}

ANDERSON, Benedict. As promessas do Estado-nação para o início do século. In: HELLER, Agnes Santos et al. A Crise dos Paradigmas em Ciências Sociais e os Desafios para o Século XXI. Rio de Janeiro: Contraponto, 1999.

BAUMAN, ZYGMUNT. Modernidade Líquida. Rio de Janeiro: Jorge Zahar Editora, 1998.

BRASIL. Constituição (1988). Brasília, DF: Senado Federal: Centro Gráfico, 1988.

IANNI, Octávio. A era do globalismo. Rio de Janeiro: Civilização Brasileira, 1996.

LARAIA, Roque de Barros. Cultura: um conceito antropológico. 14. ed. Rio de Janeiro: Jorge Zahar. 2008. 
PIERRÉ-CAPS, S. O direito das minorias. In: ROULAND, Norbert; PIERRÉ-CAPS, Stéphane; POUMMARÈDE, Jacques (Org.). Direito das minorias e dos povos autóctones. Trad. Ane Lize Spaltemberg. Brasília: Universidade de Brasília, 2004.

SOUZA, Alvaro Reinaldo de. Povos indígenas: Minorias étnicas e a eficácia dos direitos constitucionais no Brasil. Florianópolis, 2002. Mimeografado. 